\title{
Cigarette smoking, ENDS use and dual use among a national sample of lesbians, gays and bisexuals
}

\author{
Stanley L. Ridner', Jennie Z. Ma ${ }^{2,3}$, Kandi L. Walker, ${ }^{3,4}$, Thanh-Huyen T. Vu ${ }^{3,5}$, Allison Groom ${ }^{3}$, Robyn L. Landry ${ }^{3}$, Anshula \\ $K_{\text {Kesh }}{ }^{3}$, Rose Marie Robertson ${ }^{3}$, Thomas J. Payne ${ }^{3,6}$, Aida L. Giachello ${ }^{3,5}$, Lindsey A. Wood ${ }^{4}$, Joy L. Hart3,4
}

\begin{abstract}
INTRODUCTION Historically, lesbian, gay and bisexual (LGB) individuals have higher rates of cigarette smoking, often attributed to targeted tobacco advertising, exposure to stressors, and psychological distress. Elevated use of electronic nicotine delivery systems (ENDS) among LGB individuals has been documented recently. However, the LGB groups are not homogeneous and differences may exist between the use of tobacco by men and women within the LGB groups. The purpose of this research was to examine cigarette smoking, ENDS use and dual use (cigarettes plus ENDS) among LGB subgroups.

METHODS We classified 2087 participants completing a national online survey based on tobacco-use status (i.e. cigarette only, ENDS only, dual use) and sexual orientation. Multinomial logistic regression was employed to assess group differences.

RESULTS After adjusting for demographics and socioeconomic status, bisexual women were 1.85 times (95\% CI: 1.19-2.87) more likely to report current dual use, in contrast to cigarette only use, compared to heterosexual women. No significant differences were found between lesbian and heterosexual women, or between gay or bisexual men and their heterosexual counterparts.

CONCLUSIONS This study describes significantly greater dual use by bisexual women and is one of the first reports of elevated dual use in this group compared to heterosexual women. These findings suggest that targeted health messages may be needed to raise awareness of risk in specific LGB groups and that future research with these populations is necessary to better understand differences in tobacco perceptions and use.
\end{abstract}

\section{AFFILIATION \\ 1 University of South Alabama, Mobile, United States \\ 2 University of Virginia, \\ Charlottesville, United States \\ 3 American Heart Association \\ Tobacco Regulation and Addiction \\ Center (A-TRAC), Dallas, United \\ States \\ 4 University of Louisville, Louisville, United States \\ 5 Northwestern University, \\ Evanston, United States \\ 6 University of Mississippi, Jackson, United States}

\section{CORRESPONDENCE TO}

Stanley L. Ridner. University of

South Alabama, Mobile, Alabama,

United States. E-mail: ridner@

southalabama.edu ORCID ID:

https://orcid.org/0000-0002-84601596

\section{KEYWORDS}

tobacco, cigarettes, ENDS, electronic nicotine delivery systems, sexual minority

Received: 26 July 2019

Revised: 28 October 2019

Accepted: 14 November 2019

\section{INTRODUCTION}

The use of tobacco has changed dramatically over the past several years. While cigarette smoking has fallen to historic lows among US adults ${ }^{1}$, there has been a marked increase in the use of electronic nicotine delivery systems (ENDS), and approximately $4.6 \%$ of adults are current users ${ }^{2}$. In cases of dual use (both cigarettes and ENDS), recent research indicates that many dual users progress to exclusively using cigarettes ${ }^{3}$. Historically, lesbian, gay and bisexual (LGB) individuals have higher rates of smoking ${ }^{4}$, often attributed to targeted tobacco advertising ${ }^{5,6}$, exposure to stressors (i.e. minority status, stigma, homophobia, and gay bashing) $)^{7,8}$ and psychological distress 9 . The same tendency of elevated ENDS use among LGB individuals has recently been documented ${ }^{10}$. However, 
LGB groups are not homogeneous and differences may exist between tobacco use by men and women within the groups.

Compared to heterosexual women, current cigarette use (past 30 days) has been found to be consistently higher among lesbian and bisexual women ${ }^{11-16}$. A similar finding for current cigarette use was noted when comparing gay and heterosexual men $^{11-16}$, but elevated use among bisexual men has not been a consistent finding ${ }^{12-15}$.

Despite rapid proliferation of ENDS use, few studies have examined use of such devices by LGB individuals and, when investigations have occurred, the findings are less consistent than findings for cigarette smoking ${ }^{10,11,15,16}$. Current ENDS use has been found to be higher in bisexual women ${ }^{11,15}$ compared to heterosexual women, and in bisexual men ${ }^{16}$ compared to heterosexual men. No differences have been observed when comparing lesbian women and gay men to their heterosexual counterparts. One national survey found higher rates of dual cigarette and ENDS use among LGB adults, but that difference was not significant ${ }^{17}$. The purpose of this research was to examine differences in cigarette smoking, ENDS use and dual use among LGB subgroups.

\section{METHODS}

\section{Sample}

The study sample comprised 2087 individuals (918 men, 1169 women) from a national survey of adults (aged $\geq 18$ years) who were current ENDS users and/ or current cigarette smokers. Recruitment took place from 24 June to 11 August 2016 and, on behalf of the American Heart Association Tobacco Regulation and Addiction Center (A-TRAC), was conducted by Research Now and Survey Sampling International (SSI), a marketing research vendor, via their online panels and those of their partners. Approximately 13000 individuals received emails inviting them to complete the online survey, with a targeted $20 \%$ response rate. A quota sampling method was employed to ensure diversity (e.g. age, gender, race/ethnicity, sexual orientation) and the ability to compare across groups; thus, the final sample was not intended to be representative of the US population. The Institutional Review Board of the University of Mississippi Medical Center approved the study.
Once participants gave consent, they responded to a questionnaire about selected sociodemographic and economic characteristics and items about their knowledge of, attitudes toward, perceptions of, and behavior regarding an array of tobacco products, including ENDS. Participants remained anonymous, as no personal identifying information was collected.

\section{Measures}

We examined the relationship between sexual orientation and current tobacco product use, including ENDS, cigarettes, and dual use. Current ENDS users were participants who used an ENDS device within the past 30 days and had used it for 3 months or more, which is consistent with the Population Assessment of Tobacco and Health Study and other studies ${ }^{18-20}$. Current cigarette smokers were those who smoked cigarettes in the past 30 days and smoked 100 or more cigarettes in their lifetime. Current dual users were participants who currently used both ENDS and cigarettes. Participant characteristics included demographics (age, sex, race, ethnicity) and socioeconomic status (education, income, employment status), marital status, and sexual orientation.

\section{Statistical analysis}

Descriptive characteristics were expressed as frequency (\%) for all participants. Differences in the characteristics across heterosexual, lesbian, gay and bisexual participants were assessed using chi-square test. The relationship between sexual orientation and multiple tobacco use status (dual use, ENDS use only, cigarette smoking only) was examined using multinomial logistic regression ${ }^{21}$, with adjustment for age, race, ethnicity, education, income, employment status, and marital status. The adjusted odds ratio (AOR) for tobacco-product use (with cigarette smoking only as the reference outcome) and corresponding 95\% confidence intervals (CI) are reported. Separate analyses were conducted for male and female participants because men and women used tobacco products disproportionally and our objective was to evaluate the association of sexual orientation with tobacco use. A two-sided p-value $<0.05$ was considered statistically significant. All statistical analyses were performed using SAS 9.4 (SAS Institute, Cary, NC). 


\section{RESULTS}

Of the 2087 participants, gay/lesbian and bisexual participants accounted for approximately $9 \%$ of male and $19 \%$ of female participants (Table 1). Male participants were similar in age, race, education, income, and employment status across gays, bisexuals and heterosexuals. However, ethnic representation and marital status varied significantly by sexual orientation (Table 1, Males). Specifically, $74.2 \%$ of bisexual men were Hispanic compared to $50.8 \%$ of heterosexuals and $54.9 \%$ of gay men, and $76.5 \%$ of gay men and $74.2 \%$ of bisexual men were not married compared to $53.8 \%$ of heterosexuals. In contrast, female participants significantly differed between lesbians, bisexuals and heterosexuals for almost all the characteristics except employment status (Table 1, Females). For example, lesbian and bisexual women were younger and more likely to be Hispanic, unmarried, and earn less income.

For multiple tobacco use status, after adjusting for demographics, socioeconomic status, and marital status, there were no significant differences in the likelihood of current ENDS use only or dual use as opposed to cigarette smoking only between gay men and their heterosexual counterparts, or between bisexual men and their heterosexual counterparts (Table 2, Males). However, bisexual women were 1.85 times $(\mathrm{AOR}=1.85 ; 95 \% \mathrm{CI}$ :

Table 1. Characteristics of current ENDS users and or current cigarette smokers

\begin{tabular}{|c|c|c|c|c|c|}
\hline \multirow[t]{2}{*}{ Characteristics } & \multicolumn{5}{|c|}{ Vale Participants } \\
\hline & $\begin{array}{c}\mathrm{A} / \mathrm{I} \\
(\mathrm{N}=918)\end{array}$ & $\begin{array}{l}\text { Heterosexual } \\
\text { (n-836) }\end{array}$ & $\begin{array}{c}\text { Gay } \\
(n=51)\end{array}$ & $\begin{array}{c}\text { Biserual } \\
(\text { (n -31) }\end{array}$ & $p^{*}$ \\
\hline Age (years) & & & & & 0.9033 \\
\hline $18-34$ & $423(46.1)$ & $387(46.3)$ & $22(43.1)$ & $14(45.2)$ & \\
\hline $35-64$ & 495 (53.9) & $449(53.7)$ & $29(56.9)$ & $17(54.8)$ & \\
\hline Race & & & & & 0.2349 \\
\hline African American & $249(27.1)$ & $235(28.1)$ & $8(15.7)$ & $6(19.4)$ & \\
\hline White & $297(32.4)$ & $269(32.2)$ & 19 (37.3) & $9(29.0)$ & \\
\hline Other & $372(40.5)$ & 332 (39.7) & $24(47.1)$ & $16(51.6)$ & \\
\hline Ethnicity & & & & & 0.0345 \\
\hline Hispanic & 476 (51.9) & $425(50.8)$ & $28(54.9)$ & $23(74.2)$ & \\
\hline Non-Hispanic & $442(48.1)$ & 411 (49.2) & $23(45.1)$ & $8(25.8)$ & \\
\hline Education & & & & & 0.3246 \\
\hline HS or lower & $254(27.7)$ & $237(28.3)$ & $10(19.6)$ & $7(22.6)$ & \\
\hline Above HS & $664(72.3)$ & $599(71.7)$ & $41(80.4)$ & $24(77.4)$ & \\
\hline Income (US\$) & & & & & 0.9470 \\
\hline$<50000$ & $362(39.4)$ & 332 (39.7) & $19(37.3)$ & $11(35.5)$ & \\
\hline 50000-89999 & $342(37.3)$ & 311 (37.2) & $20(39.2)$ & $11(35.5)$ & \\
\hline$\geq 90000$ & $214(23.3)$ & $193(23.1)$ & $12(23.5)$ & $9(29.0)$ & \\
\hline Employment status & & & & & 0.4780 \\
\hline Employed & 716 (78.0) & $650(77.8)$ & $43(84.3)$ & $23(74.2)$ & \\
\hline Unemployed & $202(22.0)$ & $186(22.2)$ & $8(15.7)$ & $8(25.8)$ & \\
\hline Marital status & & & & & 0.0007 \\
\hline Married & $406(44.2)$ & $386(46.2)$ & $12(23.5)$ & $8(25.8)$ & \\
\hline Not married & $512(55.8)$ & $450(53.8)$ & 39 (76.5) & $23(74.2)$ & \\
\hline Tobacco-use status & & & & & 0.8618 \\
\hline Current smokers only & $212(23.1)$ & $190(22.7)$ & $14(27.5)$ & $8(25.8)$ & \\
\hline Current ENDS users only & $417(45.4)$ & $380(45.5)$ & $24(47.1)$ & $13(41.9)$ & \\
\hline Current dual users & $289(31.5)$ & 266 (31.8) & $13(25.5)$ & $10(32.3)$ & \\
\hline
\end{tabular}


Table 1. Continued

\begin{tabular}{|c|c|c|c|c|c|}
\hline \multirow[t]{2}{*}{ Characteristics } & \multicolumn{5}{|c|}{ Female Participants } \\
\hline & $\begin{array}{c}A / I \\
(N-1169)\end{array}$ & $\begin{array}{l}\text { Heterosexual } \\
\qquad(\text { (n-915) }\end{array}$ & $\begin{array}{l}\text { Lesbian } \\
(\mathrm{n}=62)\end{array}$ & $\begin{array}{l}\text { Biserual } \\
(\mathrm{n}=162)\end{array}$ & $p^{*}$ \\
\hline Age (years) & & & & & $<0.0001$ \\
\hline $18-34$ & $660(56.5)$ & $496(52.5)$ & $36(58.1)$ & $128(79.0)$ & \\
\hline $35-64$ & $509(43.5)$ & $449(47.5)$ & $26(41.9)$ & $34(21.0)$ & \\
\hline Race & & & & & $<0.0001$ \\
\hline African American & $372(31.8)$ & 309 (32.7) & $20(32.3)$ & $43(26.5)$ & \\
\hline White & $363(31.1)$ & $321(34.0)$ & $11(17.7)$ & $31(19.1)$ & \\
\hline Other & $434(37.1)$ & 315 (33.3) & $31(50.0)$ & $88(54.3)$ & \\
\hline Ethnicity & & & & & $<0.0001$ \\
\hline Hispanic & $575(49.2)$ & $424(44.9)$ & $42(67.7)$ & $109(67.3)$ & \\
\hline Non-Hispanic & $594(50.8)$ & $521(55.1)$ & $20(32.3)$ & $53(32.7)$ & \\
\hline Education & & & & & 0.0141 \\
\hline HS or lower & $343(29.3)$ & $261(27.6)$ & $19(30.6)$ & $63(38.9)$ & \\
\hline Above HS & $826(70.7)$ & $684(72.4)$ & $43(69.4)$ & $99(61.1)$ & \\
\hline Income (US\$) & & & & & 0.0109 \\
\hline$<50000$ & $622(53.2)$ & $494(52.3)$ & $25(40.3)$ & $103(63.6)$ & \\
\hline 50000-89999 & $373(31.9)$ & $303(32.1)$ & $25(40.3)$ & $45(27.8)$ & \\
\hline$\geq 90000$ & $174(14.9)$ & $148(15.7)$ & $12(19.4)$ & $14(8.6)$ & \\
\hline Employment status & & & & & 0.4063 \\
\hline Employed & $775(66.3)$ & $634(67.1)$ & 37 (59.7) & $104(64.2)$ & \\
\hline Unemployed & $394(33.7)$ & 311 (32.9) & $25(40.3)$ & $58(35.8)$ & \\
\hline Marital status & & & & & $<0.0001$ \\
\hline Married & $373(31.9)$ & $333(35.2)$ & $9(14.5)$ & $31(19.1)$ & \\
\hline Not married & $796(68.1)$ & $612(64.8)$ & $53(85.5)$ & $131(80.9)$ & \\
\hline Tobacco-use status & & & & & 0.0569 \\
\hline Current smokers only & $425(36.4)$ & 358 (37.9) & $23(37.1)$ & $44(27.2)$ & \\
\hline Current ENDS users only & $379(32.4)$ & 306 (32.4) & $20(32.3)$ & $53(32.7)$ & \\
\hline Current dual users & 365 (31.2) & $281(29.7)$ & $19(30.6)$ & $65(40.1)$ & \\
\hline
\end{tabular}

Data are expressed in N (\%), and percentages (\%) are calculated within sexual orientation categories. ${ }^{*} \mathrm{p}$-value was based on chi-squared test for all characteristics. HS: High School.

Table 2. Likelihood of current dual use (vs cigarette only use) and current ENDS use only relative to cigarette smoking, by sexual orientation, separately for male and female participants

\begin{tabular}{|c|c|c|c|c|}
\hline \multirow{2}{*}{$\begin{array}{l}\text { Vale Participants } \\
\text { Sevual orientation }\end{array}$} & \multicolumn{2}{|c|}{ Current dual use } & \multicolumn{2}{|c|}{ Current ENDS use only } \\
\hline & IOR $\left(95^{\circ} \% \mathrm{CI}\right)$ & p & $\operatorname{AOR}\left(95^{\circ} \% \mathrm{CI}\right)$ & $p$ \\
\hline Bisexual & $0.78(0.28-2.12)$ & 0.6233 & $0.72(0.29-1.83)$ & 0.4959 \\
\hline Gay & $0.53(0.23-1.20)$ & 0.1250 & $0.71(0.35-1.45)$ & 0.3475 \\
\hline Heterosexual (Ref.) & 1 & & 1 & \\
\hline Female Participants & \multicolumn{2}{|c|}{ Current dual use } & \multicolumn{2}{|c|}{ Current ENDS use only } \\
\hline Sexual orientation & AOR $\left(95^{\circ} \mathrm{CI}\right)$ & $p$ & $\operatorname{AOR}\left(95^{\circ} \% \mathrm{CI}\right)$ & $p$ \\
\hline Bisexual & 1.85 (1.19-2.87) & 0.0062 & $1.40(0.89-2.20)$ & 0.1428 \\
\hline Lesbian & $0.95(0.49-1.84)$ & 0.8785 & $0.98(0.51-1.87)$ & 0.9523 \\
\hline Heterosexual (Ref.) & 1 & & 1 & \\
\hline
\end{tabular}

Adjusted odds ratios (AOR) and 95\% confidence intervals (CI) of lesbian/gay and bisexual participants were estimated from multinomial logistic regression for multiple tobacco use response (current dual use and current ENDS use only as opposed to current cigarette smoking only). Separate analyses were performed for male and female participants, with adjustment for age, race, ethnicity, education, income, employment status, and marital status. 


\subsection{9-2.87; $\mathrm{p}=0.0062)$ more likely to report dual} use in contrast to cigarette only use compared to heterosexual women, but there was no difference in the likelihood of current ENDS only use as opposed to cigarette smoking only between bisexual and heterosexual women (Table 2, Females). Also, no significant differences were found in the likelihood of tobacco use between lesbian and heterosexual women.

\section{DISCUSSION}

Similar to the findings of Li et al. ${ }^{15}$ and Emory et al. ${ }^{11}$, our findings support that there is increased current use of ENDS among bisexual women compared to heterosexual or lesbian women when controlling for demographic variables. While Li et al. ${ }^{15}$ focused on participants aged 18-25 years, the age of our participants was similar to those of Emory et al. ${ }^{11}$ in that we recruited participants up to 64 years old. In contrast, Hoffman et al. ${ }^{16}$ found no difference in 'current' ENDS use and an increase in 'ever' ENDS use among bisexual women. When examining ENDS use in terms of 'lifetime' use, Wheldon et al. ${ }^{22}$ found lesbian and bisexual women were at greater risk compared to heterosexual women. One important finding from our study is the increased risk of dual use (ENDS and cigarettes) among bisexual women. When examining poly-tobacco use, Delahanty et al. ${ }^{23}$ found bisexual women were more likely to use two or more tobacco products compared to gay men. However, within the LGB groups, differences in the use of combustible plus non-combustible products were not found. As additional investigations take place, it is important to clarify product-use behaviors (e.g. various combinations for dual use or poly-use, frequency and intensity of use, type and contents) to more fully understand harm potential.

The findings in this study regarding men were similar to those of both $\mathrm{Li}$ et al. ${ }^{15}$ and Emory et al. ${ }^{11}$ in that there was no difference in current ENDS use when comparing gay or bisexual men to their heterosexual counterparts. In contrast, Hoffman et al. ${ }^{16}$ found a difference when comparing male bisexual ever ENDS use and current ENDS use to their heterosexual counterparts ${ }^{16}$. It is important to note that their sample contained greater than 3000 gay/bisexual men, which may have allowed for greater sensitivity to detect ENDS use differences.

\section{Strengths and limitations}

A strength of our study was the large national sample of tobacco users allowing us to stratify by sex and sexual orientation. In addition, the sex-stratified analysis of LGB participants permitted a more precise view of ENDS behaviors. Despite its strengths, our study has a number of limitations. First, the sample was not representative of the US population, limiting the nature of potential analyses. Second, the data are crosssectional; thus, we are not able to assess any changes over time. In addition, as with all survey studies, there is a risk of recall and self-report biases, and participation required internet access. Nevertheless, our findings contribute to the literature on tobacco product use by LGB groups. While we conducted separate analyses on LGB men and women, future research exploring tobacco use with the interaction of sexual orientation and sex may provide useful insights.

\section{CONCLUSIONS}

When controlling for demographic factors, there is increased likelihood of dual use, among bisexual women compared to lesbian or heterosexual women. This report is one of the first to reveal significantly elevated patterns of dual use in this group, a finding that should be further addressed in future research. These findings, especially the greater use patterns by bisexual women, suggest that targeted health messages may be needed to raise awareness of risk in specific LGB groups and that future research with these populations is necessary to better understand differences in tobacco perceptions and use.

\section{REFERENCES}

1. Drope J, Liber AC, Cahn Z, et al. Who's still smoking? Disparities in adult cigarette smoking prevalence in the United States. CA Cancer J Clin. 2018;68(2):106-115. doi:10.3322/caac.21444

2. Centers for Disease Conrol and Prevention. BRFSS Prevalences \& Trends Data. https://www.cdc.gov/brfss/ brfssprevalence/index.html. Published 2017. Accessed September 27, 2019.

3. Piper ME, Baker TB, Benowitz NL, Jorenby DE. Changes in use patterns over 1 year among smokers and dual users of combustible and electronic cigarettes. Nicotine Tob Res. 2019;ntz065. doi:10.1093/ntr/ntz065

4. Lee JGL, Griffin GK, Melvin CL. Tobacco use among sexual minorities in the USA, 1987 to May 2007: A systematic review. Tob Control. 2009;18(4):275-282. doi:10.1136/tc.2008.028241 
5. Smith EA, Offen N, Malone RE. Pictures worth a thousand words: Noncommercial tobacco content in the lesbian, gay, and bisexual press. J Health Commun. 2006;11(7):635649. doi:10.1080/10810730600934492

6. Fallin A, Davis B. LGBT organisation successfully advocated for ban on tobacco promotions in San Jose, California. Tob Control. 2016;25(5):504-505. doi:10.1136/tobaccocontrol-2015-052660

7. Remafedi G. Lesbian, gay, bisexual, and transgender youths: Who smokes, and why? Nicotine Tob Res. 2007;9(1):65-71. doi:10.1080/14622200601083491

8. Gruskin EP, Byrne KM, Altschuler A, Dibble SL. Smoking it all away: Influences of stress, negative emotions, and stigma on lesbian tobacco use. J. LGBT Health Res. 2008;4(4):167-179. doi:10.1080/15574090903141104

9. Bränström R, Pachankis JE. Sexual orientation disparities in the co-occurrence of substance use and psychological distress: a national population-based study (2008-2015). Soc Psychia-try Psychiatr Epidemiol. 2018;53(4):403412. doi:10.1007/s00127-018-1491-4

10. Huang J, Kim Y, Vera L, Emery SL. Electronic cigarettes among priority populations: Role of smoking cessation and tobacco control policies. Am J Prev Med. 2016;50(2):199209. doi:10.1016/j.amepre.2015.06.032

11. Emory K, Kim Y, Buchting F, Vera L, Huang J, Emery SL. Intragroup variance in lesbian, gay, and bisexual tobacco use behaviors: Evidence that subgroups matter, notably bisexual women. Nicotine Tob Res. 2016;18(6):14941501. doi:10.1093/ntr/ntv208

12. Johnson SE, Holder-Hayes E, Tessman GK, King BA, Alexander T, Zhao X. Tobacco Product Use Among Sexual Minority Adults: Findings From the 20122013 National Adult To-bacco Survey. Am J Prev Med. 2016;50:e91-e100. doi:10.1016/j.drugalcdep.2018.07.021

13. Gruskin EP, Greenwood GL, Matevia M, Pollack LM, Bye LL. Disparities in smoking between the lesbian, gay, and bisexual population and the general population in California. Am J Public Health. 2007;97(8):1496-1502. doi:10.2105/AJPH.2006.090258

14. Schuler MS, Rice CE, Evans-Polce RJ, Collins RL. Disparities in substance use behaviors and disorders among adult sexual minorities by age, gender, and sexual identity. Drug Alcohol Depend. 2018;189:139-146. doi:10.1016/j.drugalcdep.2018.05.008

15. Li J, Haardörfer R, Vu M, Windle M, Berg CJ. Sex and sexual orientation in relation to to-bacco use among young adult college students in the US: A cross-sectional study. BMC Public Health. 2018;18(1). doi:10.1186/s12889-018-6150-x

16. Hoffman L, Delahanty J, Johnson SE, Zhao X. Sexual and gender minority cigarette smoking disparities: An analysis of 2016 Behavioral Risk Factor Surveillance System data. Prev Med. 2018;113:109-115. doi:10.1016/j.ypmed.2018.05.014

17. Nayak P, Salazar LF, Kota KK, Pechacek TF. Prevalence of use and perceptions of risk of novel and other alternative tobacco products among sexual minority adults: Results from an online national survey, 2014-2015. Prev Med. 2017;104:71-78. doi:10.1016/j.ypmed.2017.05.024

18. Hyland A, Ambrose BK, Conway KP, et al. Design and methods of the Population Assessment of Tobacco and Health (PATH) Study. Tob Control. 2017;26(4):371-378. doi:10.1136/tobaccocontrol-2016-052934

19. Ma JZ, Hart JL, Walker KL, et al. Perceived health risks of electronic nicotine delivery systems (ENDS) users: The role of cigarette smoking status. Addict Behav. 2019;91:156-163. doi:10.1016/j.addbeh.2018.10.044

20. Vu THT, Hart JL, Groom A, et al. Age differences in electronic nicotine delivery systems (ENDS) usage motivations and behaviors, perceived health benefit, and intention to quit. Addict Behav. 2019;98:106054. doi:10.1016/j.addbeh.2019.106054

21. Hosmer DW, Lemeshow S. Applied Logistic Regression. 2nd ed. Hoboken, NJ: John Wiley \& Sons, Inc; 2000. doi:10.1002/0471722146

22. Wheldon CW, Kaufman AR, Kasza KA, Moser RP. Tobacco Use Among Adults by Sexual Orientation: Findings from the Population Assessment of Tobacco and Health Study. LGBT Health. 2018;5(1):33-44. doi:10.1089/lgbt.2017.0175

23. Delahanty J, Ganz O, Hoffman L, Guillory J, Crankshaw E, Farrelly M. Tobacco use among lesbian, gay, bisexual and transgender young adults varies by sexual and gender identity. Drug Alcohol Depend. 2019;201:161-170. doi:10.1016/j.drugalcdep.2019.04.013

\section{CONFLICTS OF INTEREST}

The authors have each completed and submitted an ICMJE form for disclosure of potential conflicts of interest. KLW reports grants from National Institutes of Health, outside the submitted work. AG, RLL and AK report grants from National Institutes of Health National Heart, Lung and Blood Institute and Food and Drug Administration Center for Tobacco Products, during the conduct of the study. JZM reports grants from National Institutes of Health National Heart, Lung and Blood Institute and Food and Drug Administration Center for Tobacco Products under Award Number P50HL120163, during the conduct of the study. RMR reports grants from National Institutes of Health National Heart, Lung and Blood Institute and Food and Drug Administration Center for Tobacco Products, and that she served as Deputy Chief Science and Medical Officer in American Heart Association, during the conduct of the study. ALG and JLH report grants from National Institutes of Health, during the conduct of the study. The rest of the authors have nothing to disclose.

\section{FUNDING}

Research reported in this publication was supported by the National Heart, Lung, and Blood Institute (NHLBI) of the National Institutes of Health (NIH) and the Food \& Drug Administration's (FDA) Center for Tobacco Products (CTP) under Award Numbers P50HL120163 and U54HL120163. The content is solely the responsibility of the authors and does not necessarily represent the official views of the NIH, the FDA, or the American Heart Association. The funding sponsors had no role in study design; data collection, analyses, or interpretation; manuscript preparation; or the decision to publish the results.

\section{PROVENANCE AND PEER REVIEW}

Not commissioned; externally peer reviewed. 